\title{
A compact internal drum test rig for measurements of rolling contact forces between a single tread block and a substrate
}

\author{
Oskar E. Lundberga,*, Ines Lopez Arteaga ${ }^{\mathrm{a}, \mathrm{b}}$, Leif Kari ${ }^{\mathrm{a}}$ \\ ${ }^{a}$ KTH Royal Institute of Technology, The Marcus Wallenberg Laboratory for Sound and Vibration Research \\ (MWL), Centre for ECO ${ }^{2}$ Vehicle Design, SE 10044 Stockholm, Sweden \\ ${ }^{b}$ Eindhoven University of Technology, Department of Mechanical Engineering, Eindhoven, The Netherlands
}

\begin{abstract}
A novel test rig design is presented which enables detailed studies of the three force components generated in the impact and release phase of rolling contact between a tyre tread block and a substrate. The design of the compact internal drum test rig provides realistic impact and release angles for the tread block-substrate contact and enables force measurements at high rolling speeds with a high signal-to-noise ratio. Measurements of the rolling contact forces are presented for different values of rolling velocity, static pre-load and acceleration. It is demonstrated that this test rig provides results which contribute to the understanding of tyre-road interaction and can be used as input to modelling-based development of both tyres and roads aiming for improved handling, safety, energy efficiency and comfort.
\end{abstract}

Keywords: Tread block; Road; Contact forces; Rubber friction; Rolling contact; Test rig

\section{Introduction}

Traction, braking and steering performance of road vehicles are determined by the forces which are transmitted within the interface between the tyre and the substrate, often referred to as the contact patch. The contact patch for a car tyre has the approximate size of the palm of the hand and the character of the forces generated within these interfaces are of vast importance for the safety and handling of road vehicles. Moreover, the rolling contact forces are also responsible for the excitation of tyre vibrations which are partly radiated as sound, partly transformed into heat (rolling resistance) and partly being further transmitted to the vehicle chassis which in turn lead to comfort issues such as interior low frequency noise and vibrations. In addition, the tyre-road contact forces generate tyre wear which due to the rubber particle emissions is not only an economic, but also an environmental/health concern. Conclusively, since a strengthened knowledge concerning the generation of tyre-road contact forces can be used to improve many

\footnotetext{
*Corresponding author, Tel.: +46 737652087

Email addresses: oskarl@kth. se (Oskar E. Lundberg), inesla@kth. se (Ines Lopez Arteaga), leifkari@kth.se (Leif Kari)
} 
features such as handling, safety, energy efficiency and comfort, there is a strong motivation for vehicle industry and research institutes to enhance the modelling methodologies related to the tyre-substrate contact force generation.

However, the modelling-based development of the tyre-substrate interaction is to a certain extent hindered by the fact that the underlying physics of the force generation are not fully understood. Therefore, methods to measure tyre-road rolling contact forces play an important role in the development of safer, less noisy and more energy-efficient road vehicles. They are used to generate empirically based knowledge and serve as validation tools in the product development cycle. Moreover, they are used in research aiming for an increased understanding of the underlying physics of contact force generation and finally; they are potentially used in real-time active control systems for improved vehicle handling and safety, i.e. electronic stability programs (ESP) with anti-lock braking systems (ABS) and traction control systems (TCS) [1].

Several test methods exist to measure the contact forces which arise in the tyre-road rolling contact. In most cases, testing is performed on complete tyres, either installed in special vehicles or in specially designed large test-rigs such as the flat track machine, the external drum or the internal drum [2]. The use of such test rigs gives valuable knowledge to research and product development since they allow for controlled studies in which a single parameter can be changed at a time. However, in the design of such measurement systems, an unfortunate difficulty inherently lies in the measurement of contact forces within the contact patch, since any physical sensor which is applied to the contact patch will itself alter the contact conditions. Hence, the rolling contact forces are usually measured indirectly in the wheel hub/wheel holder which is unfortunate since the tyre and rim structures introduce dynamic contributions to the measured hub forces. These test results will therefore differ significantly from the sought forces generated in the tyre-road contact patch. In order to get more accurate measurement results which reveal the origins of rolling contact forces between rubber and substrate, a large number of innovative measurement systems are presented in the literature. Cheli et al. [3] present a system consisting of three strain gauge sensors which are applied to a passenger car rim, intended to form part of a real-time vehicle active control system. In order to acquire the contact forces within the contact patch, a calibration procedure is presented where the structural dynamic contribution from the rim is accounted for. Aiming also for the improvement of vehicle active control systems, Braghin et al. [4] and Matsuzaki et al. [5] make use of accelerometers fixed to the inner surface of the tyre acquiring acceleration data which is processed to approximate the forces withing the contact patch. Anghelache et al. [6], Jackowski and Wieczorek [7] and De Beer et al. [8] present measurement systems which are able to measure the stress distribution within the contact patch in three orthogonal directions by introducing contact stress measuring elements as part of a substrate plate over which the tyre is rolling. A study on the correlation between pressure distribution and tyre-road rolling noise is performed by Cesbron et al. [9], covering the road surface with a very thin sheet which consists of a grid of resistive sensors. Using this system, the contact stress distribution is measured and presented for a tyre rolling on a real road surface, however only in the normal direction. Although the contact forces were not explicitly measured, it is worth mentioning the work performed by Gultlinger [10] and his predecessors who all used different versions 
of the sensor known as the Darmstadt tire sensor, which is built into a tyre tread block to measure its deformation. In contrast to the above presented measurement methods, van der Steen et al. [11], Rantonen et al. [12] and Moldenhauer [13] present different methods to measure sliding friction between a single tread block and a substrate, excluding the complete tyre structure in their measurements of contact forces. Liu et al. [14] developed a high speed rolling test rig which is used to measure the normal and longitudinal rolling contact forces between a single tread block and a steel wheel. The same test rig is more recently extended to measure also the rolling contact between a single tread block and a single stone asperity [15].

Despite the valuable insights gained from the use of existing measurement methods, there are still many unanswered questions hindering the knowledge-based and simulation-based development of both tyres and road surfaces. Since the contact forces in tyre-road rolling contact are to a large extent determined by the geometry and material properties of tread rubber and road, a need for innovative measurement methods remains which can separate the influence of these from the influence of chassis, tyre and rim structural dynamics. There is a specific lack of accurate measurement procedures which address the influence of tread block rubber and road surface properties during rolling at realistic vehicle speeds, realistic angle of impact and release and for a realistic amount of rolling resistance during normal operating conditions.

In this paper, a compact internal drum (CID) test rig design is presented which can be used to study the three components of the contact force which arise from the impact phase and the release phase of a single tread block in rolling contact with an interchangeable substrate for rolling velocities up to $60 \mathrm{~km} / \mathrm{h}$. Moreover, the angle of impact and release are-as a consequence of the novel drum design — similar to those found in real tyre-road contact. Finally, the amount of rolling resistance can be varied, mainly in order to study its influence on the longitudinal (friction) contact forces. The design of the test-rig and the calibration of force-sensors are presented in Section 2. In Section 3, the capability of the developed test rig is exemplified by presenting measured rolling contact forces between tread block and asphalt for different values of normal load, rolling velocity and amount of rolling resistance. Concluding remarks are given in Section 4. Improved handling, safety, energy efficiency and comfort are potential outcomes from the knowledge build-up which result from the measurements with the CID test rig.

\section{CID test rig}

\subsection{Structural design and operation}

In what follows, a description of the test rig design and operation is presented with reference to Fig. 1 and Fig. 2 as well as to AppendixA and AppendixB. The core of the measurement test rig is a solid metal wheel (1) within which a force link (2) is embedded, consisting of an inner pre-tensioning element, a three-axial piezoelectric force transducer and an outer pre-tensioning element. The force link is positioned and radially fixed in the solid metal wheel which has been prepared by cutting out a section which is slightly larger than the force link itself. In this way, the force link is radially fixed but at the same 
time fully decoupled from the solid wheel in the tangential direction. After the force link has been installed, a strip of tread rubber is cut out of a truck tyre retread material (see AppendixA) and glued to the circumference of the solid metal wheel, ensuring that one of the tread blocks is centered on the outer pre-tensioning element of the force link. The two adjacent tread blocks are removed from the strip (see Fig. A.9) in order to ensure that only one tread block occupies the surface of the force link. This tread block, which is the sample tread block for which contact forces are measured, is subsequently decoupled from the remaining strip of tread rubber using a hacksaw. Thereafter, the tread block periphery is grinded to ensure a homogeneous radius of the wheel. The contact forces are measured on the sample tread block when the wheel rolls on the inner surface of a drum, which is covered by an interchangeable sample substrate (3). The asphalt substrate used in this work is presented in AppendixB. The use of different substrates having the same inner radius is enabled by the possibility to easily dismantle the drum from its shaft and by the use of a mold which creates a cavity within which any chosen substrate may be fitted (see AppendixB).

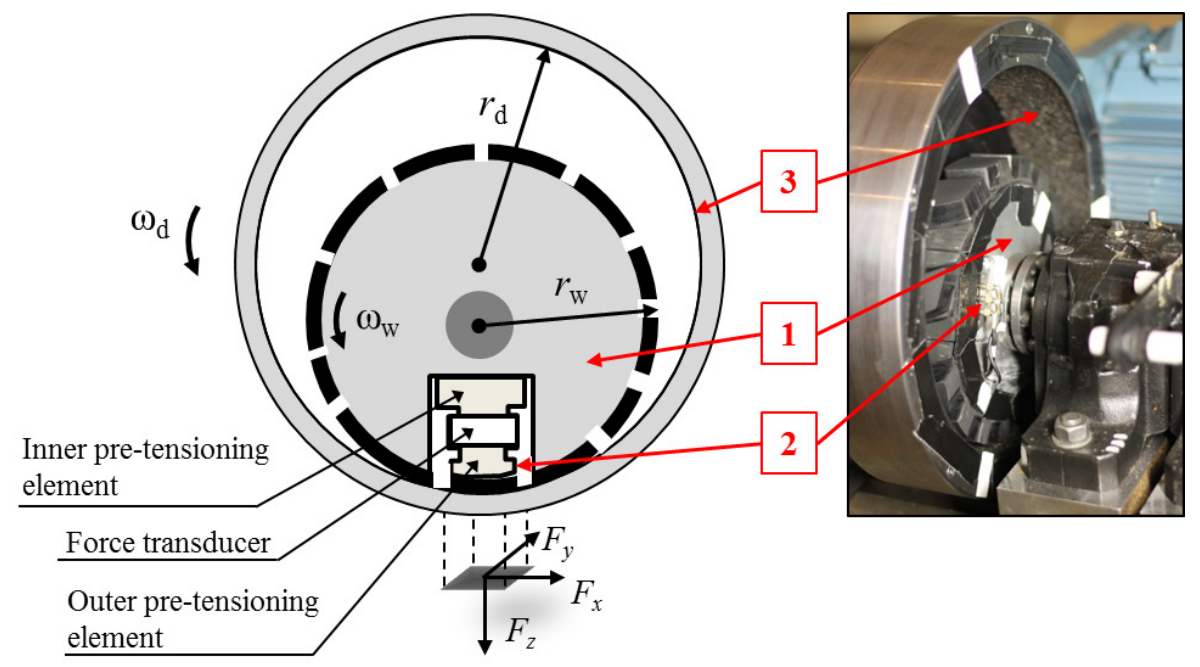

Figure 1: The core of the test rig consists of a solid metal wheel (1) within which a force link (2) including a tread block sample is embedded. In test rig operation, the solid metal wheel rolls on the inner surface of a drum (3), which is covered by an interchangeable sample substrate.

The outer radius of the solid wheel $r_{\mathrm{w}}$ and the inner radius of the drum $r_{\mathrm{d}}$ form an equivalent radius

$$
r_{\mathrm{e}}=\frac{1}{\left(1 / r_{\mathrm{w}}\right)+\left(-1 / r_{\mathrm{d}}\right)}
$$

and a corresponding impact and release angle for the rolling contact between tread block and substrate. An appropriate choice of wheel and drum radii thus enables an impact and release angle which is similar to that found in real tyre-road rolling contact. This allows for an extremely compact test rig design compared to existing internal drum testing facilities (see for instance [16]) where complete tyres are rolling on the inner surface of a 
large drum. In contrast to such facilities, the design presented in this study deliberately excludes the influence from the global tyre structural configuration in order to allow for detailed parametric studies of the influence from tread block and substrate characteristics (for instance rubber compound and substrate topography) on the resulting rolling contact forces. A corollary to the compact design is the possibility to achieve a very stiff test rig, where dynamic deformations of the test rig itself are kept as low as possible. In the design of the test rig, sub-structures and coupled structures are therefore modelled as basic elements such as beams, discs and plates for which the dynamic characteristics are well known [17]. With the basis of such modelling, both dimensions and materials are chosen as to result in high dynamic stiffness, enabling measurements with good accuracy at high rolling velocities with limited influence from the structural dynamics of the test rig itself.

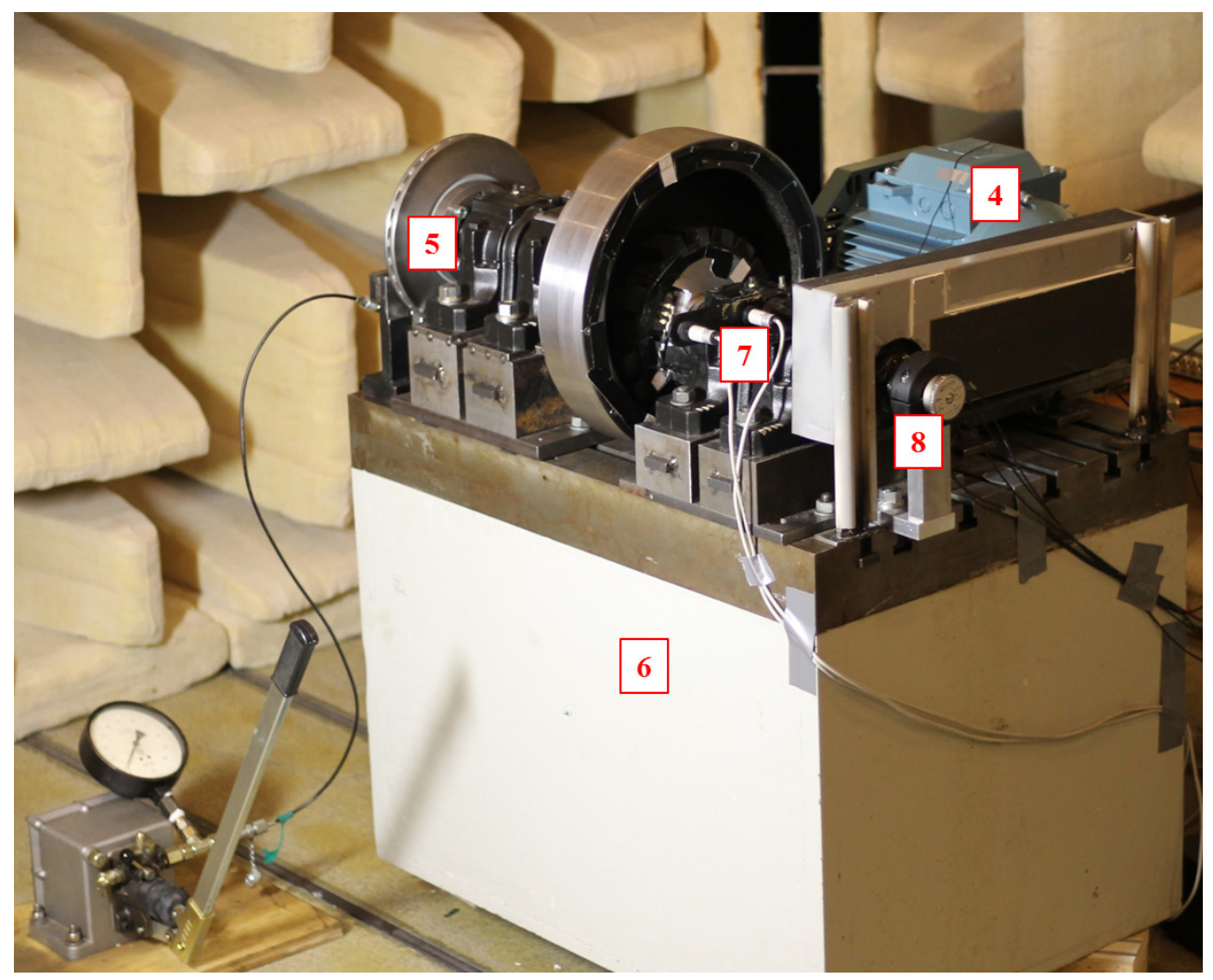

Figure 2: Overview of the test rig design with some of the components highlighted. An electric motor (4) generates torque on the solid wheel. An automotive disc brake (5) is used to brake the drum. A massive concrete block (6) gives alignment and inertia (dynamic stability) to the test rig. Optical sensors (7) are used to measure the rotational velocities of both the solid wheel and the drum. A slip ring assembly (8) is used to transfer the force and temperature signals from the rotating solid wheel to the data acquisition system.

In the operation of the test rig, a driving torque is generated by an electric motor (4) which is controlled by a drive. The torque is transferred via three transmission belts to the shaft on which the solid wheel is mounted and subsequently from the solid wheel 
to the drum via the friction forces which arise between the rubber mounted on the periphery of the solid wheel and the sample substrate on the inner surface of the drum. The shaft on which the drum is mounted is equipped with an automotive disc break (5), for which the breaking pressure can be adjusted manually with a hydraulic pump. Before operation of the test rig, a prescribed degree of compression between the tread block sample and the sample substrate is set by shifting vertically the shaft on which the drum is mounted upwards (for increased compression) or downwards (for decreased compression or complete unloading). Any prescribed degree of compression leads to a vertical static load between the tread block sample and the sample substrate which is quantified by measuring the bending strain induced in strain gauges mounted on the drum shaft (see Section 2.2). All components described above are firmly mounted on a massive concrete block (6) with the approximate mass of $2000 \mathrm{~kg}$. The rotational velocities of the solid wheel $\omega_{\mathrm{w}}$ and the drum $\omega_{\mathrm{d}}$ are measured with optical sensors (7) which are connected to a display. These are used to determine the amount of longitudinal slip [2] between the tread block and substrate defined as

$$
s_{x}=\frac{v_{\mathrm{w}}-v_{\mathrm{d}}}{v_{\mathrm{d}}},
$$

where $v_{\mathrm{w}}=\omega_{\mathrm{w}} r_{\mathrm{w}}$ is the solid wheel velocity and $v_{\mathrm{d}}=\omega_{\mathrm{d}} r_{\mathrm{d}}$ is the drum velocity. The tread block temperature during operation is measured with a resistive temperature sensor embedded in a tread block adjacent to the sample tread block which is left undamaged (see Fig. 4). A hole with the diameter of $1 \mathrm{~mm}$ is drilled from the side of the tread block in which the sensor is introduced (parallel and at a distance of $2 \mathrm{~mm}$ from the contact surface). The three-axial force transducer and the temperature sensor are both part of the rotating solid wheel. The generated signals must therefore be transmitted to the non-rotating data acquisition system and temperature display. For this, the signal cables (neutral and phase conductor) are first passed through a hole in the shaft centre and thereafter, each cable is connected to one of the connectors on a HBM SK12 slip ring assembly (8) manufactured by Hottinger Baldwin Messtechnik GmbH. Therein, each signal is connected to a silver ring which is rotating together with the shaft. On the nonrotating side of the assembly, a metal brush (one for each signal) rubs against the outside diameter of its corresponding rotating silver ring so that the signal can be conducted. The brushes are connected to cables which transmit the signals to the measurement acquisition system where the signals are sampled at the rate of $25.6 \mathrm{kHz}$.

\subsection{Design and calibration of static and dynamic force sensors}

Due to the prescribed degree of compression between tread block and substrate, a static pre-load results, which is determined indirectly by using strain gauges to measure the resulting degree of bending strain induced in the drum shaft. A calibration procedure is therefore needed in order to relate the measured shaft strain to the sought static load at the position of contact between tread block and substrate. This relation, which is presented in Fig. 3 is determined by the application of different vertical loads in the range 3 to $200 \mathrm{~N}$ at the position of contact on the drum and, for each of the vertical loads, the resulting strain (measured with the strain gauges) is registered.

The specially designed force link assembly allows measurement of vertical tensile and 
Table 1: Test rig properties.

\begin{tabular}{lll} 
Property & Symbol & Value \\
\hline & & \\
Wheel radius [m] & $r_{\mathrm{w}}$ & 0.123 \\
Drum radius [m] & $r_{\mathrm{d}}$ & 0.16 \\
Rolling velocity [kph] & & $0-60$ \\
Electric motor power [kW] & & 7.5 \\
Wheel static preload [N] & $F_{z}$ & $0-300$ \\
Radial structural resonance frequencies below $1 \mathrm{kHz}[\mathrm{Hz}]$ & $f_{\mathrm{r}}$ & 89,670 \\
Longitudinal structural resonance frequencies below $1 \mathrm{kHz}[\mathrm{Hz}]$ & $f_{\mathrm{l}}$ & 35,370 \\
\hline
\end{tabular}

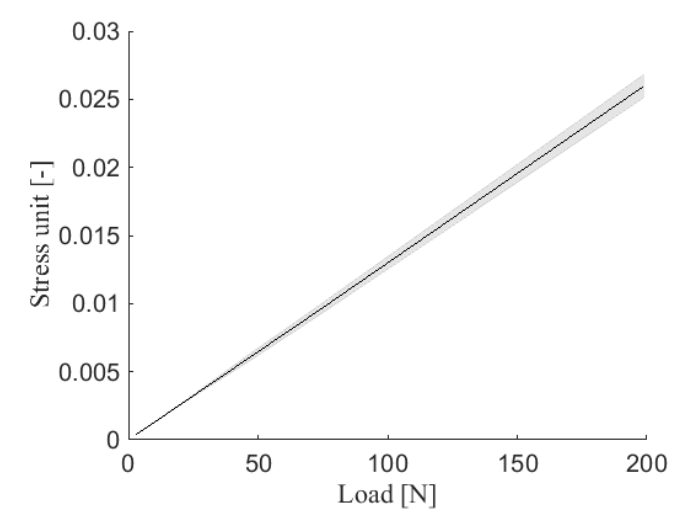

Figure 3: Relation between applied load at contact position and stress measured in drum shaft with two standard deviations above and below the curve-fitted values (shaded).

compressive forces as well as the corresponding forces in lateral directions. To this end, the three-axial piezoelectric force transducer is vertically pre-loaded with approximately $20 \mathrm{kN}$, enabling a large measuring range for tensile forces. Moreover, this ensures that the available friction force between the force transducer and the pre-loading elements well exceeds the maximum friction force between the tread block sample and the substrate. In order to provide good signal-to-noise ratio for the output electric charge obtained from the piezoelectric force transducer (which is only in the order of a few nC) an amplification is required close to the transducer output which is commonly provided by a standard charge amplifier. However, the environment close to the force transducer is subject to large dynamic inertial forces due to high speed rotation which are likely to introduce measurement noise in the amplification. Due to the low electric charge output, positioning the charge amplification after the slip ring assembly would also result in poor signal to noise ratio. Instead, a built-in charge amplifier fed with a constant current is prepared for each of the three force signals and positioned close to the transducer as part of the solid wheel, schematically shown in Fig. 4.

The calibration of the pre-loaded dynamic force link was performed by measuring 


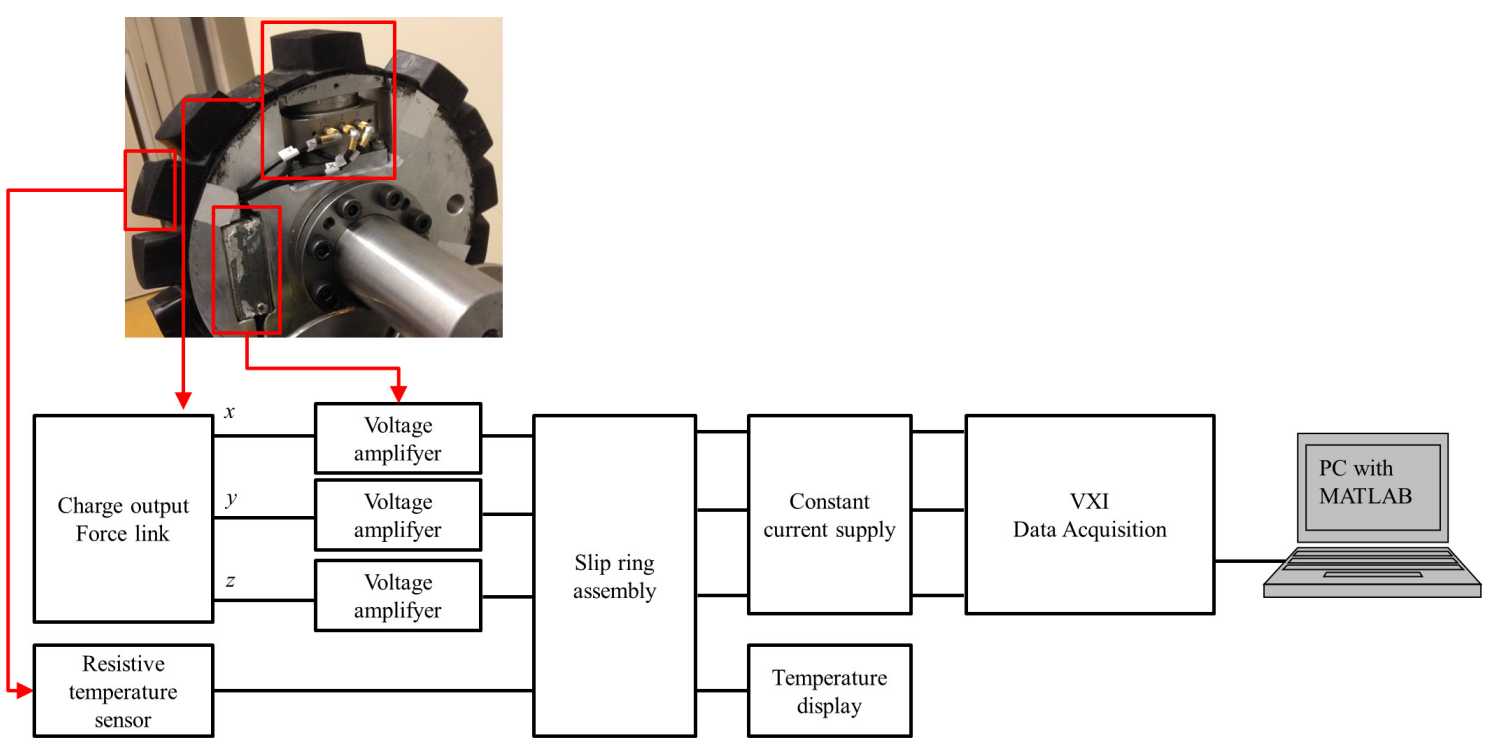

Figure 4: Schematic figure of measurement chain for the dynamic force-signals and the temperature measurement.

its output signal when mounted in a dynamic testing machine (Instron Model 8032) and comparing the signal with that of a calibrated force transducer. In this way, the force link sensitivity was determined for sinusoidal displacement with the amplitude of approximately $5 \mu \mathrm{m}$ in the frequency range 10 to $70 \mathrm{~Hz}$. The results from the calibration procedure are presented in Fig. 5.

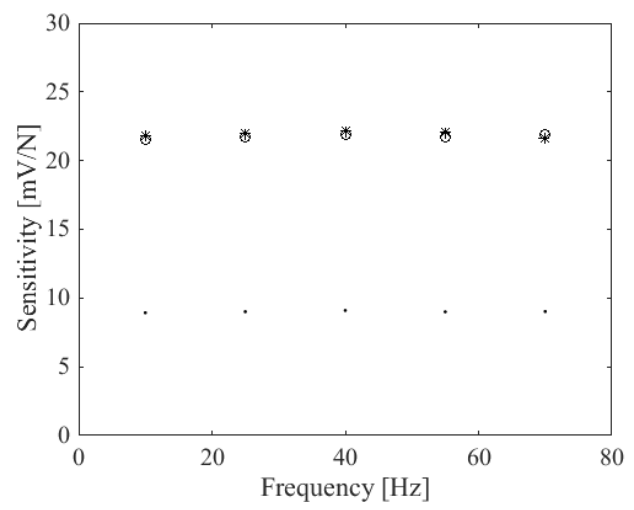

Figure 5: Measured sensitivity for vertical $z$ (dots), longitudinal $x$ (stars) and transverse $y$ (circles) force components and five frequencies at the displacement amplitude of $5 \mu \mathrm{m}$. 


\section{Examples of results from measurements of rolling contact forces}

The dynamic contact forces in the longitudinal $(x)$, transverse $(y)$ and vertical $(z)$ directions are measured for a sample truck tyre tread block in rolling contact with a sample asphalt substrate. The resulting contact forces are presented in Fig. 6 together with the corresponding longitudinal coefficient of friction

$$
\mu=\frac{F_{x}}{F_{z}}
$$

for a rolling velocity $v_{\mathrm{d}}$ of $3.6 \mathrm{~m} / \mathrm{s}$ and a vertical static load of $70 \mathrm{~N}$. The friction coefficient is only defined for the case when the tread block is in contact with the substrate. The vertical compression of rubber leads to vertical compressive stresses as well as longitudinal shear stresses directed towards the center of the contact area. A sinusoidal-like longitudinal force history is found since the tread block is deformed towards the leading edge at impact and subsequently deformed towards the trailing edge in the release phase. In Fig. 6 a), this sinusoidal-like character is distorted by a superimposed shear force directed towards the leading edge which correspond to the force required to overcome the rolling losses of the test rig and maintain a constant velocity. The force history immediately after the driving torque has been removed is presented in Fig. 6 b), where the superimposed longitudinal shear force is directed towards the trailing edge. This sinusoidal-shaped force history is found in numerous experimental investigations of the longitudinal forces on complete rolling tyres $[7,8,18,19,20]$ as well as in the investigation of a single tread block in rolling contact performed by Liu et al. [21]. These references also present a measured amplitude ratio between longitudinal and normal force components which is in the same order of magnitude as that of the friction coefficients presented in Fig. $6 \mathrm{c}$ ) and d). Due to the asymmetry of the tread block shape (leading and trailing edge are not perpendicular to the direction of travel), also a transverse shear force is measured, although it is small in comparison with both the vertical and the longitudinal force components.

Constant acceleration is simulated by the application of a braking torque to the drum and simultaneously a driving torque generated by the electric motor sufficient to maintain a constant rolling velocity. In Fig. 7 a) and b), the resulting contact forces are presented for simulated constant acceleration at the rolling velocity $3.6 \mathrm{~m} / \mathrm{s}$. The corresponding friction coefficients, which are presented in Fig. 7 c) and d), are seen to reach values well above one which is supported by experimental results presented by Kröger and Moldenhauer [22] and by van der Steen [23]. The measured slip values corresponding to the acceleration shown in Fig. 7 a) and b) are 0.038 and 0.100 , respectively.

The resulting contact forces from an increased rolling velocity to $11.2 \mathrm{~m} / \mathrm{s}$ are presented in Fig. 8. Higher vertical contact forces are measured, which might be explained by a larger dynamic stiffness for the rubber at higher frequencies. Moreover, the higher rolling velocity implies a shorter contact time, thus leading to more narrow peaks for the time history of the vertical contact force compared to those presented in Fig. 6 and Fig. 7. The sinusoidal character of the longitudinal force component in Fig. 8 a) is present also for the higher rolling velocity. When a braking torque is applied and the driving torque is adjusted so that a constant rolling velocity is maintained, an additional force 


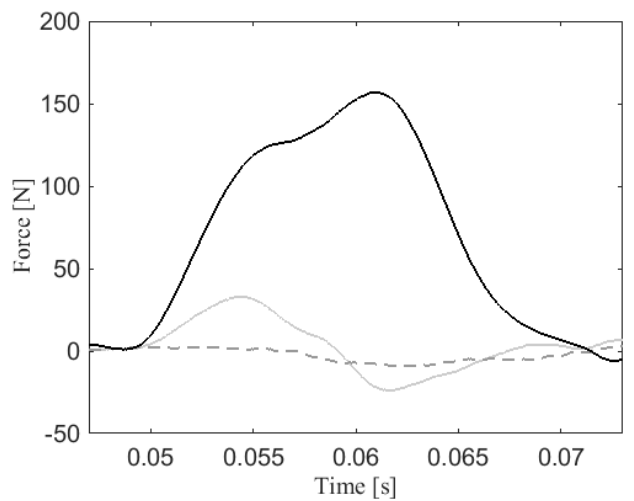

(a)

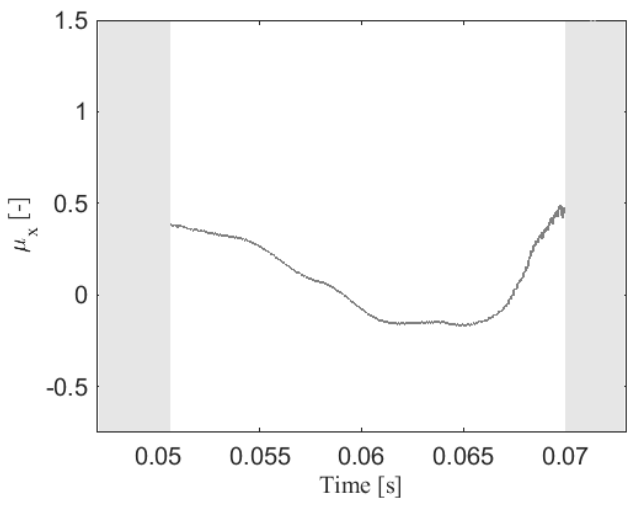

(c)

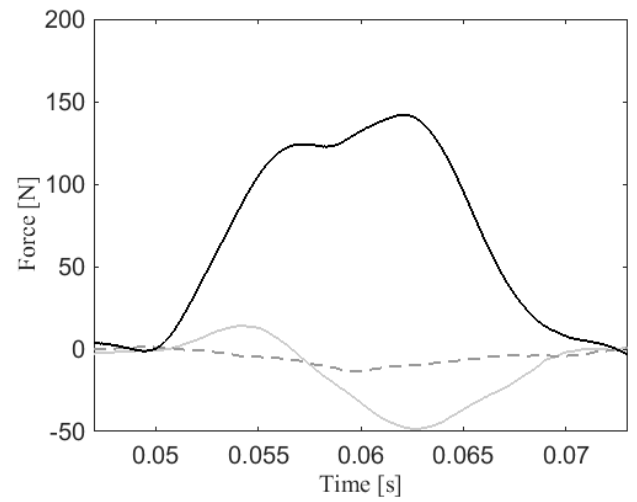

(b)

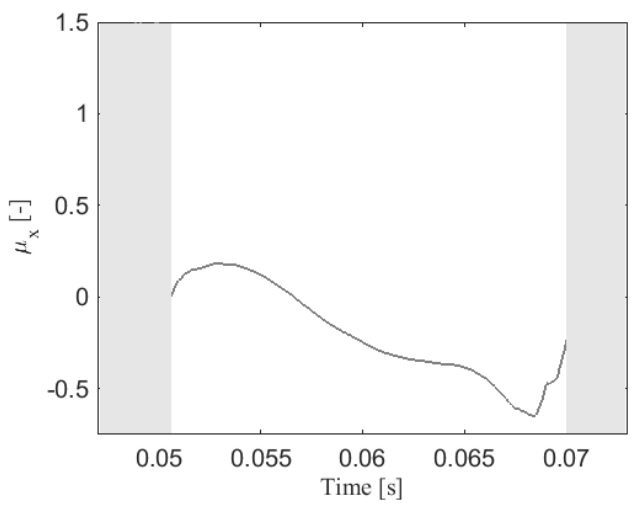

(d)

Figure 6: Measured longitudinal (solid grey), transverse (dashed) and vertical (solid black) contact forces for rolling velocity $3.6 \mathrm{~m} / \mathrm{s}$ and static load $70 \mathrm{~N}$; (a) with driving torque; (b) without driving torque; (c) longitudinal friction coefficient with driving torque during the time of contact; (d) longitudinal friction coefficient without driving torque during the time of contact.

directed towards the leading edge is, in Fig. $8 \mathrm{~b}$ ), seen to superimpose the sinusoidal free-rolling character of the longitudinal force component. The higher rolling velocity in combination with the higher vertical contact forces is clearly seen to dynamically excite the tread block and cause force oscillations which remain even after the tread block has completed its path through the contact patch. These oscillations could originate from the structural dynamics of both the tread block as well as from the test rig structure.

\section{Conclusions}

A novel test rig is developed for measurements of the forces in the impact and release phase of a tyre tread block in rolling contact with a substrate. Due to its design which is 


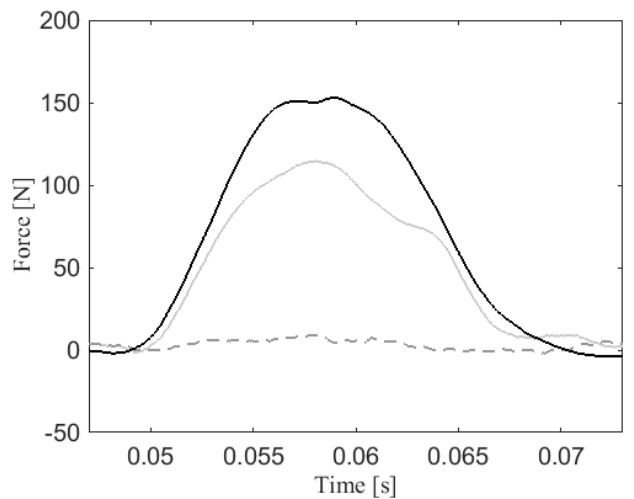

(a)

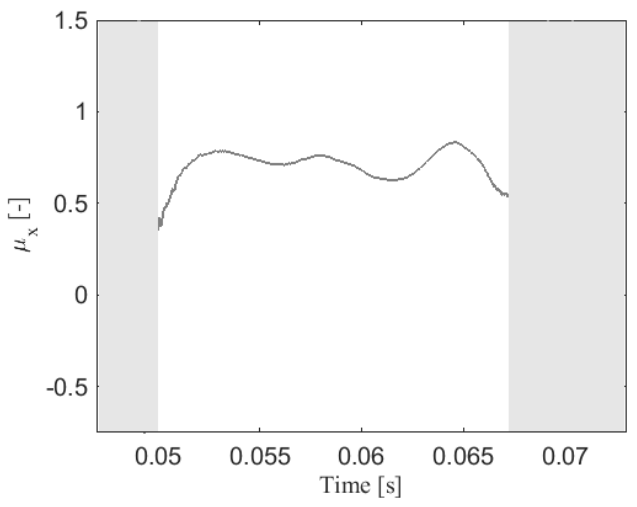

(c)

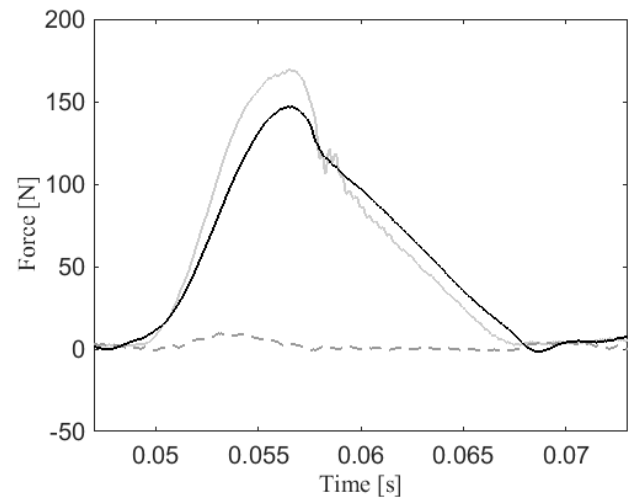

(b)

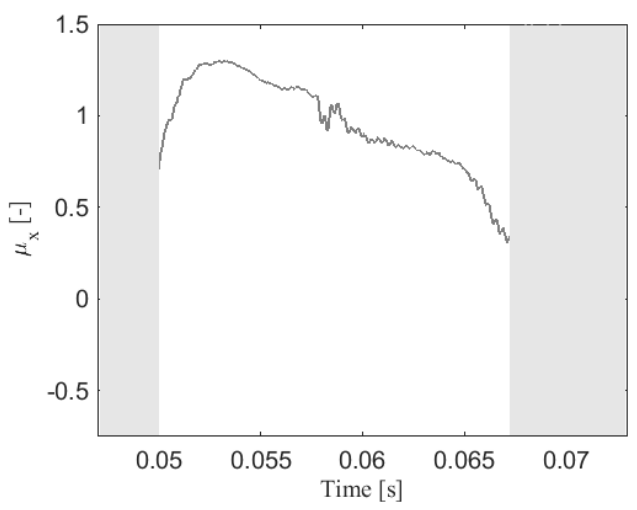

(d)

Figure 7: Measured longitudinal (solid grey), transverse (dashed) and vertical (solid black) contact forces for rolling velocity $3.6 \mathrm{~m} / \mathrm{s}$ and static load $70 \mathrm{~N}$; (a) with driving torque and braked drum $\left(s_{x}=0.038\right)$; (b) with driving torque and heavily braked drum $\left(s_{x}=0.100\right)$; (c) longitudinal friction coefficient with driving torque and braked drum during the time of contact; (d) longitudinal friction coefficient with driving torque and heavily braked drum during the time of contact.

based on the internal drum measurement principle, the test rig is referred to as a compact internal drum test rig. However, instead of incorporating a complete tyre, a sample tread block is the object of study. This enables the impact and release angle to be similar to that found in real tyre-road contact. Moreover, the test rig is extremely compact which allows for a stiff structural design and consequently a low influence from the structural dynamics of the test rig itself. The test rig can be run at velocities up to $60 \mathrm{~km} / \mathrm{h}$ and the degree of vertical compression can be altered in order to simulate different vehicle loads. The presented test rig is highly suitable for detailed investigations of the influence from rubber tread block and substrate characteristics on the resulting rolling contact forces since both the substrate as well as the sample tread block are fully interchangeable. Also, since the dynamic contribution from the tyre structure is omitted in the presented 


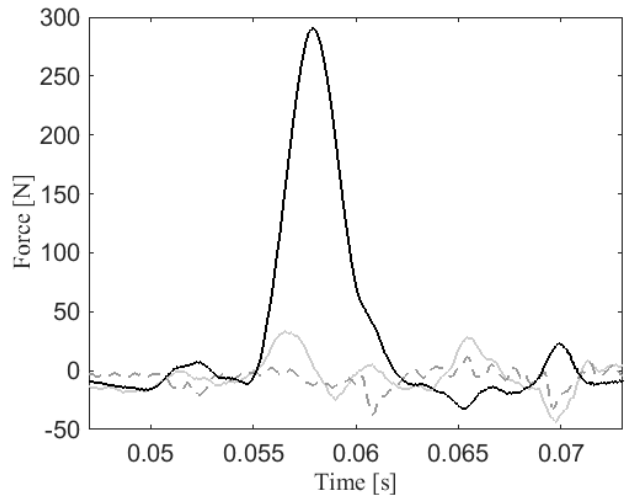

(a)

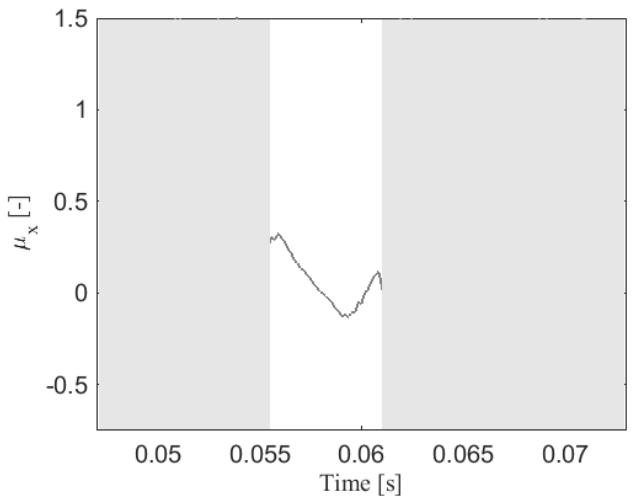

(c)

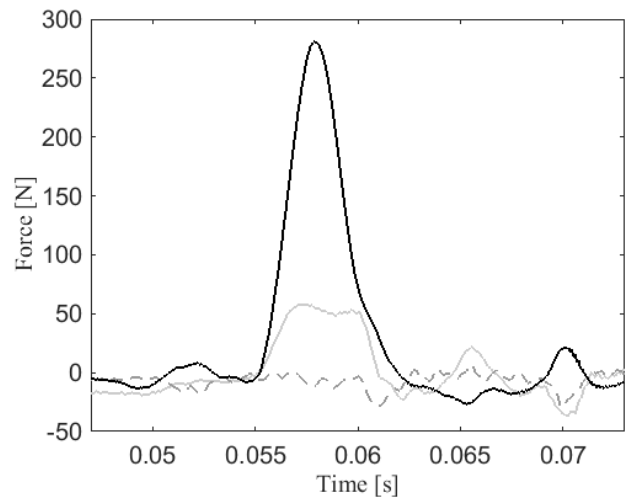

(b)

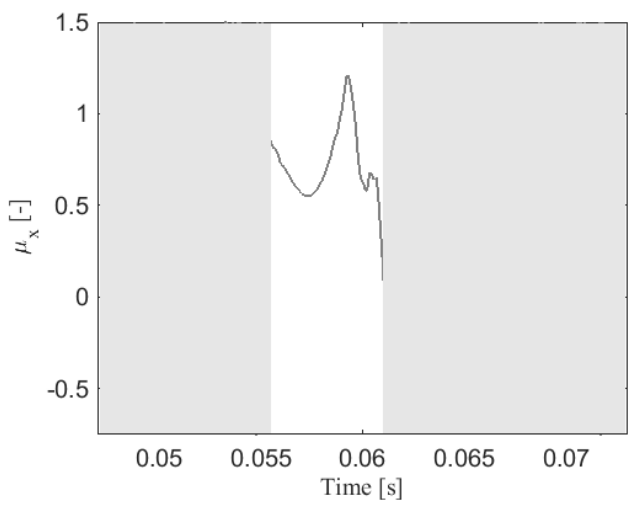

(d)

Figure 8: Measured longitudinal (solid grey), transverse (dashed) and vertical (solid black) contact forces for rolling velocity $11.2 \mathrm{~m} / \mathrm{s}$ and static load $100 \mathrm{~N}$; (a) with driving torque ( $s_{x}=0.016$ ); (b) with driving torque and braked drum $\left(s_{x}=0.028\right)$; (c) longitudinal friction coefficient with driving torque during the time of contact; (d) longitudinal friction coefficient with driving torque and braked drum during the time of contact.

CID test rig design, the possibility to study tread block and substrate-related influence on the resulting contact forces is enhanced. A high signal-to-noise ratio is achieved for the force signals through integrated voltage amplification as part of the rotating wheel.

The capability of the test rig to measure details of the rolling contact forces between tread block and substrate is assessed by presenting results for different rolling velocities and for different static vertical pre-loads. In addition, results were presented for both free-rolling condition as well as for accelerating condition. 


\section{Acknowledgements}

The Centre for $\mathrm{ECO}^{2}$ Vehicle Design is gratefully acknowledged for financially supporting this work. Further, the first author would like to specially acknowledge the important contributions from laboratory technician Danilo Prelevic and electric measurement specialists Kent Lindgren and Uno Persson, all affiliated to the Marcus Wallenberg Laboratory for Sound and Vibration Research. The help received from Kenneth Duvefelt at the Department of Machine Design, KTH Royal Institute of Technology when measuring the substrate surface texture is most appreciated. Finally, Euromaster AB is acknowledged for providing tread rubber and BINAB/NCC Roads likewise for providing asphalt for the study.

\section{AppendixA. Tread block parameters}

The tread sample used for the study is a commercial retread material for a truck tyre in drive position which is optimised for regional and long haul traffic [24]. The product name is Michelin $\mathrm{XDA}^{\circledR} \mathrm{PM}^{\mathrm{TM}}$ Retread. The strip of tread material which was cut out and used in the study is shown in Fig. A.9 together with the tread block dimensions.
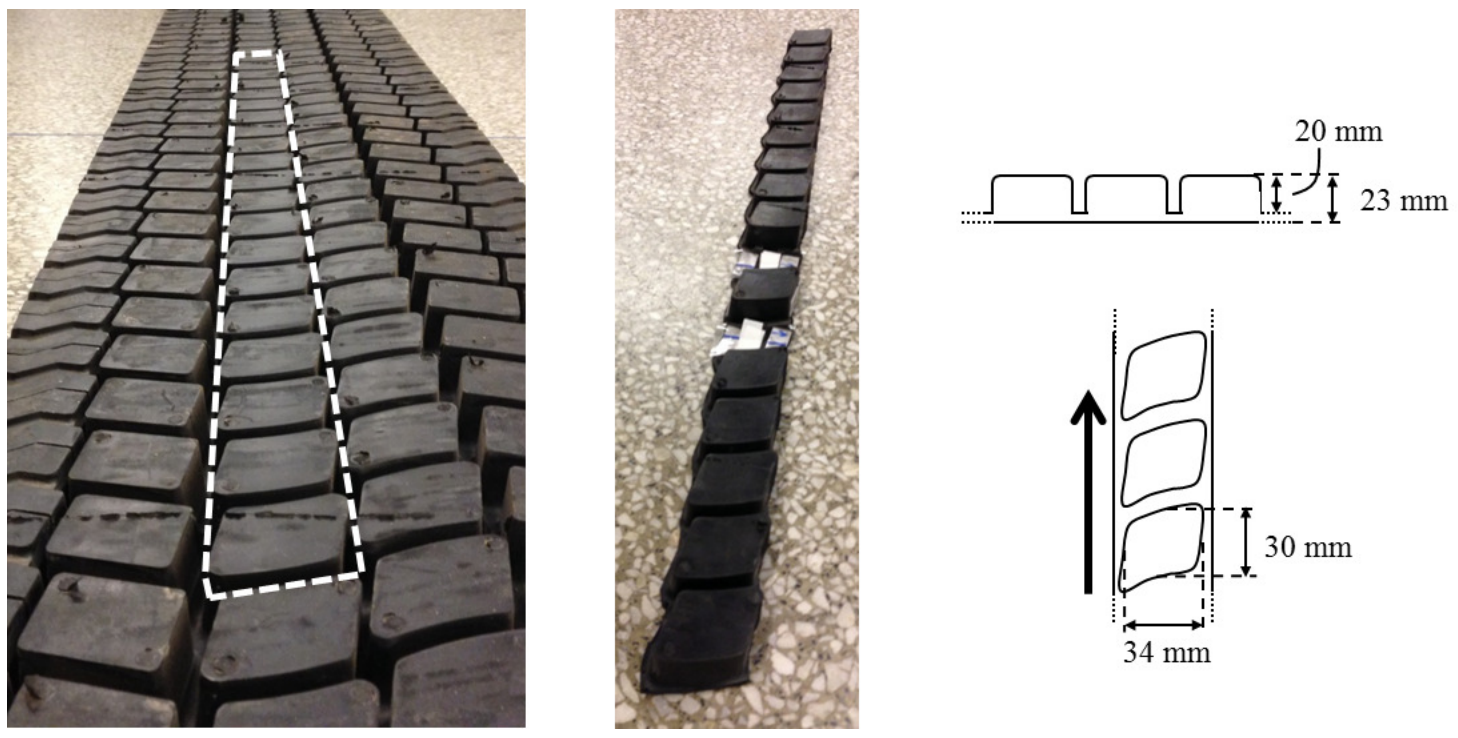

Figure A.9: A strip of tread was cut out of the retreading material. A sketch shows the dimensions of the tread block (top view) and the arrow indicates the rolling direction used in the study. 


\section{AppendixB. Substrate properties}

The asphalt substrate used in this work has the properties presented in Table B.2. The surface topography is measured using optical fringe projection with the GFM Primos Compact camera manufactured by GFMesstechnik GmbH. The spatial resolution is 66 $\mu \mathrm{m}$ and the height resolution is $4 \mu \mathrm{m}$ over the measurement area $30 \times 40 \mathrm{~mm}^{2}$ [25]. The resulting surface texture is ensemble averaged over two surface scans and presented in Fig. AppendixB as the surface power spectral density defined as in Ref. [26]

$$
C(\mathbf{q})=\frac{1}{(2 \pi)^{2}} \iint\langle h(\mathbf{x}) h(\mathbf{0})\rangle \mathrm{e}^{-i \mathbf{q} \mathbf{x}} \mathrm{d}^{2} \mathbf{x} .
$$

Table B.2: Properties of the asphalt substrate used in this study.

\begin{tabular}{ll} 
Property & Value \\
\hline Product & NCC Repasfalt / Vialit Reaktiv Asphalt ${ }^{\circledR}$ \\
Type & Fast hardening reactive asphalt which cures with water \\
& and air humidity in cold condition. \\
Layer thickness [mm] & 25 \\
Maximum stone size $[\mathrm{mm}]$ & 4 \\
\hline
\end{tabular}

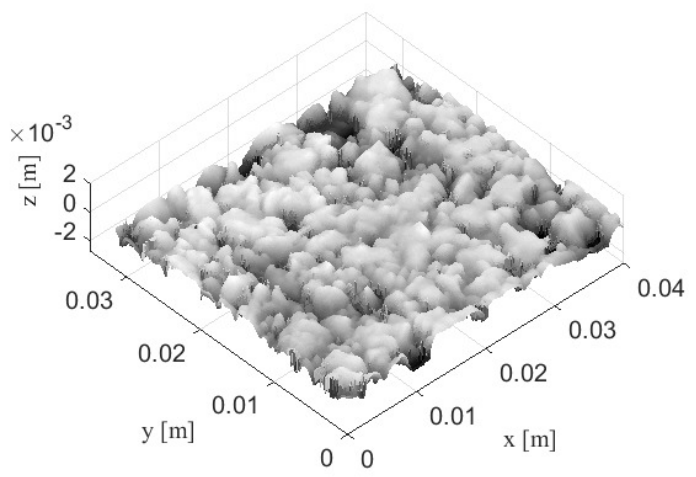

(a)

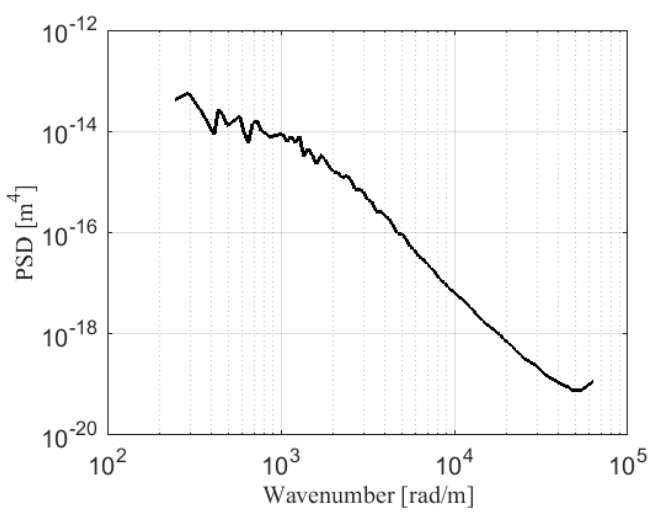

(b)

The drum can easily be dismantled from its shaft in order to prepare or change the substrate. In Fig. B.10, a schematic figure shows how a mould is created by accommodating a cylinder in the centre of the drum. The cavity formed between the cylinder and the metal frame of the drum has the width of $25 \mathrm{~mm}$ and axial depth of $60 \mathrm{~mm}$. The mould ensures a constant nominal inner radius of the drum independently of the chosen substrate. The preparation of asphalt substrates as the one presented in Table 
B. 2 is fast and practical since it cures within approximately 24 hours at normal room temperatures after adding water or humidity. Moreover, the asphalt adheres to the metal frame using conventional asphalt primer. However, any deformable substrate material which can cure within the cavity or any solid material which is accurately fabricated to fit the cavity and adhere to the metal frame can be used.

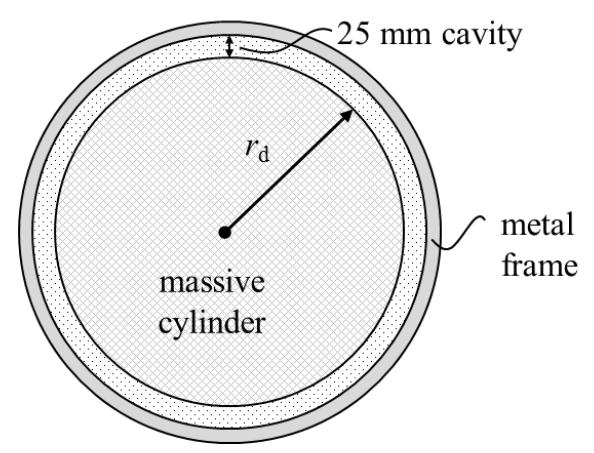

Figure B.10: A mould for the substrate is created by accommodating a massive cylinder in the centre of the drum, leaving a cavity (dotted) between the drum metal frame and the cylinder. A substrate of choice is accommodated within this cavity. 


\section{References}

[1] C. C. de Wit, P. Tsiotras, E. Velenis, M. Basset, G. Gissinger, Dynamic friction models for road/tire longitudinal interaction, Vehicle System Dynamics: International Journal of Vehicle Mechanics and Mobility 39 (2003) 189-226.

[2] H. Pacejka, Tire and vehicle dynamics, Elsevier, 2012.

[3] F. Cheli, F. Braghin, M. Brusarosco, F. Mancosu, E. Sabbioni, Design and testing of an innovative measurement device for tyre-road contact forces, Mechanical Systems and Signal Processing 25 (2011) 1956-1972.

[4] F. Braghin, M. Brusarosco, F. Cheli, A. Cigada, S. Manzoni, F. Mancosu, Measurement of contact forces and patch features by means of accelerometers fixed inside the tire to improve future car active control, Vehicle System Dynamics: International Journal of Vehicle Mechanics and Mobility 44 (2006) 3-13.

[5] R. Matsuzaki, K. Kamai, R. Seki, Intelligent tires for identifying coefficient of friction of tire/road contact surfaces using three-axis accelerometer, Smart Materials and Structures 24 (2015) 025010.

[6] G. Anghelache, R. Moisescu, S. Sorohan, D. Buretea, Measuring system for investigation of tri-axial stress distribution across the tyre-road contact patch, Measurement 44 (2011) 559-568.

[7] J. Jackowski, M. Wieczorek, Analysis of interaction between tyre tread and road on the basis of laboratory test, in: Transbaltica, 2011.

[8] M. D. Beer, C. Fischer, Stress-in-motion (sim) system for capturing tri-axial tyreroad interaction in the contact patch, Measurement 46 (2013) 2155-2173.

[9] J. Cesbron, F. Anfosso-Lédé, D. Duhamel, H. P. Yin, D. L. Houédec, Experimental study of tyre/road contact forces in rolling conditions for noise prediction, Journal of Sound and Vibration 320 (2009) 125-144.

[10] J. Gültlinger, Kraftübertragung und fahrbahn-verschleiß durch spikereifen, Ph.D. thesis, Karlsruher Institut für Technologie (2015).

[11] R. van der Steen, I. L. Arteaga, H. Nijmeijer, Experimental and numerical study of friction and stiffness characteristics of small rolling tyres, Tire Science and Technology 39 (2011) 5-19.

[12] M. Rantonen, A. Tuononen, P. Sainio, Measuring stud and rubber friction on ice under laboratory conditions, International Journal of Vehicle Systems Modelling and Testing 7 (2012) 194-207.

[13] P. Moldenhauer, Modellierung und simulation der dynamik und des kontakts von reifenprofilblöcken, Ph.D. thesis, Technischen Universität Bergakademie Freiberg (2010). 
[14] F. Liu, M. P. F. Sutcliffe, W. R. Graham, Modeling of tread block contact mechanics using linear viscoelastic theory, Tire science and technology 36 (2008) 211-226.

[15] F. Liu, M. P. F. Sutcliffe, W. R. Graham, Prediction of tread block forces for a freerolling tyre in contact with a rough road, Wear 282-283 (2012) 1-11.

[16] K.-P. Glaeser, W. Bartolomaeus, Vehicle-pavement interaction facility (pff), Tech. rep., Federal Highway Research Institute (Germany) (2014).

[17] R. D. Blevins, Formulas for natural frequency and mode shape, Van Nostrand Reinhold Company, 1979.

[18] G. Anghelache, R. Moisescu, O. Ciubotaru, C. Dragomir, Investigation of automotive tire contact stress under real rolling conditions, SAE Technical Paper Series 01 (2005) 1822.

[19] R. A. Douglas, W. D. H. Woodward, A. R. Woodside, Road contact stresses and forces under tires with low inflation pressure, Canadian Journal of Civil Engineering 27 (2000) 1248-1258.

[20] F. Klempau, Untersuchungen zum aufbau eines reibwertvorhersagesystems im fahrenden fahrzeug, Ph.D. thesis, Technischen Universität Darmstadt (2003).

[21] F. Liu, M. P. F. Sutcliffe, W. R. Graham, Prediction of tread block forces for a freerolling tyre in contact with a smooth road, Wear 269 (2010) 672-683.

[22] M. Kröger, P. Moldenhauer, Influences on the vibration frequencies of tire tread blocks, in: Proceedings of ISMA2010, 2010.

[23] R. van der Steen, Enhanced friction modeling for steady-state rolling tires, Ph.D. thesis, Eindhoven University of Technology (2010).

[24] Leaflet: Michelin retread technologies $x{ }^{\circledR}{ }^{\circledR}$ pre-mold ${ }^{\mathrm{TM}}$ retread.

[25] K. B. K. Duvefelt, U. L.-O. Olofsson, C. M. J. Johannesson, Towards simultaneous measurements of skin friction and contact area: Results and experiences, Journal of Engineering Tribology 229 (2015) 230-242.

[26] B. N. J. Persson, Theory of rubber friction and contact mechanics, Journal of Chemical Physics 115(8) (2001) 3840-3861. 